\title{
LO NOVEDOSO EN LAS ARTES VISUALES ARGENTINAS DE LOS AÑOS 70. EL CASO DE MENDOZA
}

\author{
María Paula Pino Villar ${ }^{4}$
}

RESUMEN: El presente trabajo pretende identificar las distintas posiciones que emergen de los debates sobre las nuevas formas de expresión en las artes visuales durante los años 70, a partir del caso de la provincia de Mendoza (Argentina). Las diversas posiciones sobre lo nuevo son aquí necesariamente situadas en relación con su recepción dentro del campo artístico. Asimismo, nos preocupa identificar cuáles fueron los agentes artísticos asociados a prácticas novedosas y cómo se produjo su divulgación. Es decir, a partir de qué medios circularon las ideas sobre lo novedoso en las artes visuales y quiénes fueron las personas o instituciones que colaboraron en este proceso. Para ello se trabajó con distintas fuentes escritas de la época, tanto revistas culturales como Claves, Cinco para todos... y Enfoques; también con periódicos, como el Diario Mendoza y Los Andes; y con catálogos de exposiciones. El recorrido por las fuentes descriptas permite reconstruir el entramado de las ideas que los artistas sostuvieron sobre su práctica y conocer las respuestas que dieron al interrogante sobre cómo debía ser el arte. Si entendemos la irrupción del Pop art y el cinetismo como novedad en el campo artístico mendocino, podemos entender la recepción de estas nuevas formas de expresión como alternativas de lo nuevo en el campo artístico visual de Mendoza.

Palabras clave: Artes visuales; Arte argentino; Arte mendocino; Vanguardia; Santángelo.

ABSTRACT: the present work attempts to identify the different positions that emerge within the discussions over the new forms of expression of the visual arts in the case of Mendoza (Argentina) during the

${ }^{4}$ Becaria doctoral del Instituto de Ciencias Humanas, Sociales y Ambientales, Centro Científico Tecnológico, CONICET Mendoza. Magíster en Arte latinoamericano y Licenciada en Historia del Arte por la Facultad de Artes y Diseño, Universidad Nacional de Cuyo. Docente de Arte y Contexto de la misma facultad. 
70s. The many positions on 'the new' are necessarily nestled in relation to their reception within the art field. Likewise, the concern is to identify the artistic agents associated to some innovative practices and how they managed to spread their work. That is, by what means the ideas about 'the new' within the visual art field circulated and who -either people or institutions - collaborated in the process. In order to do so, different written sources from the 70s were taken: cultural magazines such as Claves, Cinco para todos... and Enfoques together with newspapers like Mendoza and Los Andes and some exhibition catalogues. The path record of the mentioned sources allows the reconstruction of the ideas' scheme that the artists held over their practice and the answers they gave to the question on how art should be. Understanding the irruption of Pop art and Kinetic Art as innovations within the Mendocinean art field allows for the comprehension of the reception of these new forms of expression as alternatives of 'the new' within the art field in Mendoza.

Keywords: Visual arts; Argentinean art; Mendocinean art; Vanguardism; Santángelo.

\section{Introducción}

Antes de iniciar el recorrido sobre las concepciones de "lo nuevo" en las artes visuales, nos parece importante realizar algunas aclaraciones sobre la periodización propuesta. En términos de la Historia de las ideas, Claudia Gilman (2012) entiende las décadas del 60 y 70 como parte de un bloque temporal que conforma una misma época. A su vez, la autora define época como "el campo de lo que es públicamente decible y aceptable -y goza de la más amplia legitimidad y escucha- en cierto momento de la historia" (GILMAN, 2012: 36). Este bloque temporal inicia en 1959 con la Revolución cubana y se cierra con el golpe de Estado de 1976. Es decir: entre el estallido revolucionario y hasta su clausura definitiva por parte de las dictaduras militares en el Cono Sur. La autora encuentras que esta época se caracteriza por la valorización de la política y la expectativa revolucionaria.

Por su parte, refiriéndose a estos años en Argentina, Oscar Terán (2008) describe los vínculos entre el campo intelectual y político como una "relación triangular entre modernismo, radicalismo y tradicionalismo" (TERÁN, 2008:284).

De manera análoga, esta relación triangular define tres subperiodos sucesivos en las artes visuales mendocinas. Un primer 
Lo Novedoso en las artes visuales argentinas de los años 70. El caso de Mendoza | 29

momento, que podríamos definir vinculado a la vanguardia modernista entre 1969-1972; un segundo momento de radicalización política entre 1973-1976; y finalmente, la clausura de todos los discursos relativamente autónomos del arte con la imposición del tradicionalismo bajo el gobierno militar, a partir del golpe de Estado del 24 de marzo de 1976. El inicio de nuestro período de análisis coincide con el momento en que se imponen en la provincia de Mendoza las tendencias cinéticas y el Pop art. Durante este primer período, de 1969-1972, los debates se dieron en torno al deseo de "modernizar" el arte. Seguidamente, entre 1973-1976 tenemos un momento en que se borran las fronteras entre acción política y acción artística que dan origen a un "arte para la revolución" (LONGONI, 2014). Los artistas se sienten interpelados por el estallido social conocido como Mendozazo (1972) y progresivamente su discurso se irá empapando de las discusiones sobre el populismo y el nacionalismo que dominaban el campo intelectual argentino de los setenta. Por último, el tercer momento se identifica con el tradicionalismo militar y se dio entre 1976-1979. Inclusive a partir de 1978 se percibe una voluntad institucional de promover el tradicionalismo y los valores, que se evidencia en las exposiciones realizadas en el Museo de Arte Moderno de Mendoza. Llama la atención el uso reiterado que se hace en los catálogos de estas exposiciones sobre la función del arte en relación a los valores, que en ninguno de los casos se explicitan. Sin embargo, basándonos en el trabajo de Terán (2008) quien encuentra que el marco ideológico general de la dictadura argentina fue "armado con las viejas piezas del catolicismo integrista y antimodernista, en tiempos del anticomunismo maccartista, y animados por un impulso de cruzada religiosa" (TERÁN, 2008:297), es que podemos deducir que estos valores coinciden con los del catolicismo integrista.

En miras de abordar las ideas sobre "lo nuevo" aquí profundizaremos solamente el primer momento de la vanguardia modernista (1969-1972). En este la discusiones en torno al "arte actual", "de nuestros días", "vanguardista" son recurrentes. Los diagnósticos sobre el panorama de la plástica no son homogéneos y se distinguen dos posiciones contrarias, cuyas diferencias se tornan evidentes al pronunciarse sobre la irrupción del Pop art y el cinetismo en la provincia.

Por su parte, Víctor Godgel (2013) al estudiar las valoraciones sobre lo nuevo en América latina, distingue entre dos posiciones: "la de quienes creen en la ruptura y la de quienes se muestran escépticos" (GODGEL, 2013:18). Si entendemos la irrupción del Pop art y el 
cinetismo como novedad en el campo artístico mendocino, podemos entender la recepción de estas nuevas formas de expresión como valoraciones alternativas de lo nuevo en el campo artístico visual de Mendoza.

\section{Debates en torno a la irrupción del pop art}

El inicio de nuestro período de análisis coincide con el momento en que se imponen en la provincia de Mendoza las tendencias abstractas y el Pop art. Así lo consideraba el artista Raúl Capitani en una nota que ofrece al Diario Mendoza en octubre de 1969. En la misma se entrevista a varios artistas y se les pregunta "cuál es el estado actual de la plástica". Puntualmente el periodista le cuestiona a Capitani sobre cuáles considera que son las tendencias que predominan en el medio, a lo cual responde diciendo que

(Se) imponen las abstractas como el pop art que parecen nuevas y no son sino teatro y aparatosidad. Son como las modas femeninas o los cantantes de moda, hay que cambiarlos de cartelera semanalmente. Lo obligan al artista a hacer esto, y mañana aquello. Lo convierten en bufón. Pasa lo que con los críticos, que en lugar de orientar al público, apoya la aventura, incitan a ella. No al trabajo creador, sino a la simple, peligrosa tendencia, de querer ser diferente (MENDOZA, 19 de octubre de 1969).

A su consideración sobre las tendencias que se imponen, se suma el hecho de que abril de 1970 se presenta en el Museo Municipal de Arte Moderno de Mendoza la primera muestra de Pop art en la provincia. La misma contó con el auspicio del Servicio Cultural e Informativo de los Estados Unidos, se exhibieron afiches ilustrativos de esta tendencia, al tiempo que se exaltaron "las posibilidades comerciales del afiche pop centrando en ello la historia del movimiento" (CHIAVAZZA, abril 2016).

La exposición de afiches Pop realizada en el Museo de Arte Moderno confirma lo observado por Capitani sobre el momento de irrupción de las tendencias cercanas al Pop art y nos permite asegurar que es a principios de 1970 que Mendoza toma contacto con ellas. Cabe 
Lo Novedoso en las artes visuales argentinas de los años 70. El caso de Mendoza | 31 advertir que en el caso de Buenos Aires este proceso venía gestándose desde mediados de los años 60.

La irrupción del Pop en Buenos Artes es anterior a lo que mencionamos sobre Mendoza. Entre los meses de mayo y junio de 1966, se realizó en el Instituto Di Tella la exposición 11 artistas pop: la nueva imagen, con obras de los célebres de la tendencia: Roy Lichtenstein Andy Warhol, Jim Dine, Allen Jones, Tom Wesselmann y otros (Ver Imagen 1 en Apéndice). Del mismo modo que en la exposición de afiches de Mendoza, también 11 artistas pop fue auspiciada por el Servicio Cultural de los Estados Unidos ${ }^{5}$. Otros acontecimientos que dan cuenta de la irrupción el Pop art en Buenos Aires son las dos conferencias tituladas Arte pop y semántica que Oscar Masotta dictó en el Di Tella en septiembre de 1965, y que dieron origen a la posterior publicación de su libro El popart en 1967 (MASOTTA, 2004).

Las exposiciones realizadas en el Instituto Di Tella que promovieron las expresiones ligadas al Pop ejercieron gran influencia en la artista mendocina Iris Mabel Juárez. Algunas de ellas fueron el Premio Internacional Di Tella de 1965, que otorgó el primer premio a James Rosenquist y la sucesiva realización del Premio Nacional Di Tella, donde el crítico británico que acuñó el término Pop art, Lawrence Alloway, subrayó la importancia de la ciudad de Buenos Aires con respecto a esta tendencia 6 .

Junto a Beatriz Santaella, Juárez viajó frecuentemente a Buenos Aires para mantenerse actualizadas sobre las últimas tendencias de la plástica, y en la Argentina de los años 60 la meca de lo novedoso era sin lugar a dudas el Di Tella. Ambas artistas están directamente asociadas a la vanguardia modernista de Mendoza. Ello se debe a las características formales de sus pinturas, reconocidas en los años 70 por sus pares artistas como expresiones novedosas, pero también debido al posicionamiento que adoptaron sobre la plástica mendocina (Ver Apéndice. Imágenes 2 y 3). Asimismo, Juárez junto al Profesor Abdulio Giúdice y Beatriz Santaella

\footnotetext{
${ }^{5}$ En esta ocasión puntual se agregaron en la realización conjunta Phillips Morris Internacional y el Centro de Artes Visuales del Di Tella.

6 "Buenos Aires ha sido desde hace algunos años una ciudad con una importante actividad de los artistas Pop y con un potencial mayor aún. Es claro que con el Premio Di Tella 1966 ahora es uno de los más vigorosos Centros del Pop Art en el mundo". (Alloway, Lawrence. [El único rasgo singular del Premio Di Tella 1966]. Manuscrito tipeado. Archivos Di Tella, Universidad Torcuato Di Tella, Buenos Aires.)
} 
tuvieron un papel importante como divulgadores del pop y las tendencias cinéticas en la provincia de Mendoza.

En el artículo publicado en la Revista Enfoques el mismo año de la exposición de afiches Pop, Iris Mabel Juárez describe el "Panorama de la Plástica mendocina" desde una perspectiva opuesta a la que mencionaba Capitani pero con algunos puntos en común:

Casi con total seguridad puede asegurarse que nuestro arte plástico no vive ni acepta la vanguardia que este tiempo y este momento exigen. Salvo valiosas excepciones éste está nutrido por una excesiva dosis de convencionalismo que impide la libre manifestación de expresiones progresistas. Movimientos como el Pop art, que tuvimos ocasión de apreciarlo en dos o tres oportunidades, el $\mathrm{Op}$ art realizado con toda calidad por artistas mendocinos, manifestaciones cinéticas traídas desde Bs. As., todos ellos debieron enfrentarse con la frialdad y apatía de este medio, aún el artístico, que intenta por diversos medios frustrar cualquier tipo de resonancia (JUÁREZ, 13 de junio de 1970: 13)

Como puede observarse en sus palabras, Juárez percibe el medio plástico mendocino como atrasado respecto a las expresiones progresistas que identifica con el Pop art, el Op art y "manifestaciones cinéticas traídas desde Bs. As" (JUÁREZ, 13 de junio de 1970: 13) Asimismo, describe dos tomas de posición dentro del campo artístico: por un lado se hallan los "dueños de la cultura", con "excesivas dosis de convencionalismo que impide la libre manifestación de las expresiones más progresistas”, a quienes la autora les atribuye acciones obstaculizadoras para preservar tal estado de las cosas. Del lado contrario, se hallan las "valiosas excepciones", entre las que encuentra las tendencias vinculadas al Pop art.

Resulta significativo cómo en la elocuencia de su descripción, Juárez ilustra una de las principales características que Pierre Bourdieu (1997) le atribuye al campo artístico. El autor define este microcosmos social como el espacio de relaciones objetivas entre posiciones, que adquieren sentido si se sitúa a cada agente o institución en su relación objetiva con 
Lo Novedoso en las artes visuales argentinas de los años 70. El caso de Mendoza | 33

los demás. Bourdieu incluso precisa que es en el horizonte particular de estas relaciones de fuerza específicas, y de las luchas que pretenden conservarlas o transformarlas, donde se engendran las estrategias de los productores, las formas de arte que preconizan, etc. (BOURDIEU, 1997) Es decir, que podríamos entender los debates en torno a la irrupción del Pop art como el campo de batalla entre posiciones que definen el campo artístico de Mendoza en los 70.

También podemos reconocer en Capitani y Juárez las dos posiciones de sujeto que distingue Víctor Godgel (2013) al estudiar las valoraciones sobre lo nuevo en América Latina. La postura de Juárez sería análoga al "punto de vista que preserva el atractivo de la novedad -con sus connotaciones modernas de mejora, liberación, originalidad, etc." (GODGEL, 2013:19). Mientras que la percepción de Capitani sobre el Pop, puede leerse a tono con la posición que "produce cierto escepticismo hacia lo (supuestamente) nuevo y lo entiende, antes que nada, como una suerte de ilusión: simple efecto retórico o, en todo caso, variación del uso y la función de elementos culturales ya disponibles." (GODGEL, 2013:19).

\section{Redes intelectuales y circulación de imágenes}

Tanto Raúl Capitani como Iris Mabel Juárez, fueron premiados en el Certamen Bienal Municipal de 1971, lo cual da cuenta de que ambos eran reconocidos en el campo artístico mendocino durante el período. Raúl Capitani obtuvo el Primer premio en la categoría de Dibujo y grabado con su obra Eco de multitudes, mientras que I.M. Juárez obtuvo el tercer premio en la misma categoría por su dibujo Ventanas de la realidad.

Siguiendo otro de los índices de reconocimiento artístico, en términos de circulación de imágenes, las obras de Capitani tuvieron proyección a nivel nacional y regional. El artista participó junto a Gastón Alfaro y Luis Cíceri en la exposición de Poemas Ilustrados de Ricardo Tudela, Víctor Cúneo, Enrique Ramponi y Armando Tejada Gómez, entre otros, que se realizó en agosto de 1974, en la Galería Meridiana de Buenos Aires. En la misma ciudad por encargo de la galería Esmeralda, realizó en 1972 la serie "Los niños de nuestro tiempo", que fue editada como carpeta de estampas en una tirada de 200 ejemplares que contaron con el prólogo del célebre grabador porteño Víctor Rebuffo.

Otra instancia de circulación importante fue la participación de Raúl Capitani como ilustrador del № 24 de la revista Crisis, publicado en 
abril de 1975, dado que la misma resulta emblemática entre las revistas argentinas con distribución latinoamericana de los años 70. Su cuerpo editorial contó, entre otros, con Eduardo Galeano como director, Juan Gelman en la redacción y entre las variadas colaboraciones gráficas también participó el mendocino Enrique Sobisch en el No40, publicado en agosto de 1976. Si bien las afinidades políticas de Crisis fueron disímiles, mayormente se la asocia corrientes de izquierda, el peronismo y el nacionalismo populista. Aunque la ilustración de Capitani que finamente se publica en Crisis no da cuenta de ello, el artista es "un referente del arte comprometido, es decir, un arte al servicio de la revolución social, tal como se entendía por los 60 y 70. Un arte figurativo, de denuncia de las iniquidades de la explotación social. Expresionista y oscuro." (ZALAZAR, 24 de abril - 26 de mayo de 2014: s/n)

El espacio expositivo que en Mendoza supo nuclear a artistas con búsquedas similares a las de Raúl Capitani durante los años 70, fue el Taller Nuestro Teatro. Entre las numerosas actividades que allí se realizaban, encontramos la presentación de espectáculos teatrales -su principal actividad-, pero además se proyectaban películas, se realizaron talleres, exposiciones de artes visuales y también espectáculos musicales. Como ejemplo de la variedad de actividades y convergencia en el Taller Nuestro Teatro de mendocinos con proyección nacional y referentes del arte comprometido, encontramos la noticia del Diario Mendoza del 4 de septiembre de 1972. En la misma se anuncia la presentación de Armando Tejada Gómez conjunto se alude a la exposición de grabados de Carlos Alonso recientemente inaugurada.

Será este mismo espacio el que reúna a Iris Mabel Juárez y Raúl Capitani en una misma exposición. Se trató del Homenaje a Sergio Sergi, realizado en agosto de 1973. El catálogo de la exposición fue escrito por Fernando Lorenzo, quien también se desempañaba como columnista de la revista Claves. En octubre del mismo año, en esta revista Lorenzo reseña la exposición realizada en el Museo de Arte Moderno con motivo del XXII Salón de Cuyo, en homenaje a Sergio Sergi y Pablo Picasso, la cual prácticamente replica la realizada en el Taller Nuestro Teatro. En su reseña Lorenzo se refiere al "centenar de cultores de las artes visuales" que participan de la exposición, entre los que menciona el grabado "de corte neto, tradicional y siempre ajustado de Raúl Capitani (Nuestro tiempo I grabado en plástico)" y a la "única obra pop de la exposición" refiriéndose 
Lo Novedoso en las artes visuales argentinas de los años 70. El caso de Mendoza | 35 a la pintura de Iris Mabel Juárez, titulada Gardel ${ }^{7}$ (LORENZO, 6 de octubre de 1973: 32-33).

El repertorio temático que Juárez llevó a sus pinturas fue el de las figuras mediáticas de la época, tanto del mundo del espectáculo como de la política. Aunque su obra más reproducida probablemente haya sido el Gardel que describe Lorenzo, Juárez también retrató en clave pop a Salvador Allende, José Ignacio Rucci y el Ché Guevara. Estas últimas representaciones la llevaron a ocultar su obra Pop desde el golpe del 24 de marzo de 1976 y hasta avanzados los años '80, momento durante el cual esta vertiente de su producción se interrumpió de forma definitiva para dar lugar a otras búsquedas.

En relación a las discusiones que en torno del Pop art estaban sucediendo en Latinoamérica, es importante recuperar el trabajo de Marta Traba (1973), donde la autora describe el estado del arte entre 1950-1970 a partir de "tres síntomas": el renacimiento del dibujo, el erotismo como valor y la nacionalización del pop-art. En cuanto a éste último, Traba puntualiza como los "nuevos pop se manejan con elementos locales" (TRABA, 1973:168) sin abandonar los planos netos de color unido, claramente discernibles, realizados con acrílico o pinturas sintéticas, en cuya caracterización coincide totalmente con las pinturas pop de Iris Mabel Juárez.

Modernismo en Mendoza. Entre la feria de América y la creación del Museo de arte moderno

El espíritu de vanguardia se había hecho presente en Mendoza desde los años 50. El carácter internacionalista que el Segundo Plan Quinquenal del gobierno peronista tradujo en el envío nacional a la Segunda Bienal de São Paulo en 1953 tuvo también su propio exponente en Mendoza, a partir de la realización de la Feria de América, entre enero y abril de 1954. Inspirada en las grandes exposiciones internacionales que desde 1851 se realizaban en distintas partes del mundo, la feria contó con pabellones destinados a las provincias argentinas, los organismos estatales, agrupaciones industriales y varios países invitados de Latinoamérica (QUIROGA, 2012).

Lo que vuelve a esta feria significativa para el arte de vanguardia, es la participación del diseñador Tomás Maldonado ${ }^{8}$ y el arquitecto César

\footnotetext{
${ }^{7}$ Ver Apéndice Imagen 3
} 
Janello. Junto a Gerardo Clusellas realizan la Torre Alegórica "que contó con un sistema de sincronización de luces y de música compuesta por Mauricio Kagel. Los organizadores formalizaron normas de diseño y construcción general para mantener un espíritu coherente, modernista y avanzado del conjunto de la exposición” (QUIROGA, 2012).

La realización de la Torre Alegórica en la Feria de América, sienta un precedente en Mendoza en la creación de obras plurisensoriales, que incorporan luz y sonido, pues contó con música de Mauricio Kagel, que sonaba en sincronía con el encendido de luces que destacaban la composición basada en módulos triangulares. Al mismo tiempo, el lenguaje abstracto geométrico de ambos, junto con el ideario de Janello, cercano a los planteos de la Bauhaus y el movimiento de artes y oficios, dejaron una huella en los talleres de la Escuela Superior de Cerámica, e incluso fueron la base para la creación de la carrera de Diseño de la Universidad Nacional de Cuyo, en 1958.

A partir de 1955 en Argentina comienza a constituirse un circuito modernizador conformado por nuevas instituciones del arte, como el Museo de Arte Moderno de Buenos Aires y del Instituto Di Tella, ambos fundados en 1960. También Mendoza comenzaba a constituir su propio circuito modernizador, es en este sentido que debe considerarse como hecho fundacional la creación del Museo de Arte Moderno, en 1967.

\section{La vanguardia modernista}

Ahora bien, es conveniente hacer algunas aclaraciones sobre lo enunciado por Juárez y este primer momento de la vanguardia modernista. Ésta se relaciona con las expectativas del modelo desarrollista en Argentina, que en el campo artístico adquiere expresión en el deseo de "modernizar" el arte. Aquí las tensiones centro/periferia serán definitorias, principalmente, en tanto se percibe lo propio como atrasado, y lo del centro como "de vanguardia". Esta representación, en la esfera nacional se encarna en la figura del crítico Jorge Romero Brest ${ }^{9}$ y su deseo

8 Tomás Maldonado (1922, Buenos Aires) pintor, dibujante publicitario, diseñador industrial y teórico del diseño argentino. Creó la Asociación de Arte Concreto Invención, fue profesor y director de la Escuela Superior de Diseño de Ulm (Alemania)

${ }^{9}$ Jorge Romero Brest (1905-1989) fue un profesor, crítico y gestor en el campo de las artes visuales argentinas. Dirigió la revista Ver y Estimar. Más tarde, el gobierno de facto autodenominado Revolución Libertadora, lo nombró Interventor del 
Lo Novedoso en las artes visuales argentinas de los años 70. El caso de Mendoza | 37

de actualizar e internacionalizar el arte argentino, salvarlo del hermetismo de los años de oscuridad ${ }^{10}$ como se refirió a los primeros gobiernos de Juan Domingo Perón. Romero Brest operó eficazmente para cumplir con las expectativas de la nueva burguesía industrial aliada al capital internacional, de volver a la ciudad de Buenos Aires capital internacional del arte, principalmente como director del Centro de Artes Visuales del Instituto Di Tella.

Este deseo de modernización cultural, que tradicionalmente se asocia al Instituto Di Tella, formó parte de un proyecto más amplio y general de la renovación en el ámbito de la cultura. Otro sintoma conocido de este proceso fue la realización de las Bienales Americanas de Arte en Córdoba, patrocinadas por la empresa automotriz Industrias Kaiser Argentina, entre 1962 y 1966 (ROCCA, 2009). Las Bienales de Córdoba, igual que muchas de las exposiciones y becas impulsadas por el Di Tella, y la exposición de afiches Pop que se realizó en el Museo de Arte Moderno de Mendoza, supieron canalizar la política exterior norteamericana en el marco de la Guerra Fría (GIUNTA, 2001; ROCCA, 2009).

Asimismo, pese a la voluntad emancipatoria que en esta época gestó la corriente de pensamiento vinculada a la Filosofía de la Liberación $^{11}$, existe un consenso que reconoce entre los artistas latinoamericanos una tendencia a defender la modernización cultural y mostrarse abiertos al contacto con las culturas internacionales. Consideramos que esto se debe a dos motivos: por un lado, al trauma "provocado por las formas del arte oficial soviético y el stalinismo y las poéticas del realismo y el sentimentalismo." Pero también, al hecho de que los artistas latinoamericanos, aunque adhirieran al socialismo,

Museo Nacional de Bellas Artes de Buenos Aires, donde, en 1956, asumió como director hasta 1963. En la década de sesenta estuvo al frente del Centro de Artes Visuales del Instituto Torcuato Di Tella.

${ }^{10}$ Para ampliar sobre la lectura de Jorge Romero Brest sobre el campo cultural argentino durante los años del peronismo se recomienda: Dolinko, S. Lecturas de Jorge Romero Brest sobre la Bienal de Venecia. Figuraciones. Teoría y critica de las artes. $\mathrm{N}$ 10, septiembre de 2012

11 Sobre este aspecto se recomienda: Beorlegui, Carlos, Capítulo 10. La generación de los años setenta. Las filosofias de la liberación In Historia del pensamiento filosófico latinoamericano. Una búsqueda incesante de la identidad. Bilbao: Universidad de Deusto, 2004 
"estaban estéticamente más cerca de los Estados Unidos y Europa" (GILMAN, 2012: 66-68).

Entre los artistas e intelectuales mendocinos, la tendencia a defender la modernización cultural puede reconocerse en el Panorama de la Plástica mendocina realizado por Iris Mabel Juárez. Pero esta voluntad de modernización que agitaba las búsquedas plásticas de Santaella como a las reflexiones teóricas y la producción Pop de Juárez, se halla directamente vinculada a la actividad docente del Profesor Abdulio Giudici ${ }^{12}$. Fue en las clases de Historia del Arte que impartía Giudici en la Escuela Superior de Artes $^{13}$ de la Universidad Nacional de Cuyo, donde estudiantes como Iris Mabel Juárez y Beatriz Santaella tomaron contacto el op-art. Oriundo de Buenos Aires y egresado de la Escuela Nacional de Bellas Artes Prilidiano Pueyrredón, Giudici es un pilar central para comprender la difusión de las tendencias abstracto geométricas asociadas al modernismo vanguardista en el campo artístico de Mendoza.

Siguiendo la iniciativa de Giudici, se realizaron entre septiembre de 1966 y agosto de 1969 una serie de conferencias y cursillos en el Museo de Arte Moderno de Mendoza que pretendían "facilitar la comprensión de las situaciones culturales y humanas que crea el arte moderno" (GIUDICI, 1966). A juzgar por las palabras de presentación de la primera de estas actividades, donde se plantea la premura y la urgencia de conocer el arte contemporáneo, podemos rastrear en la percepción del Profesor Giúdici indicios sobre esta necesidad de modernización cultural, que agitó a la vanguardia modernista. Así como animó a sus estudiantes a viajar para mantenerse actualizadas sobre las últimas tendencias del arte, Giudici también realizaba viajes anuales a los centros del arte del momento, entre ellos Nueva York. Asimismo, su relación con César Janello, ambos impulsores de la creación del Departamento de Diseño y Decoración de la Escuela Superior de Artes, nos conduce a pensar en una sociabilidad propiciatoria del surgimiento de la vanguardia modernista mendocina. Esta red de relaciones que se inicia con la Feria de América, Tomás Maldonado y César Janello, pasando por la mediación del profesor Abdulio Giúdici hasta llegar a las más jóvenes Iris Mabel Juárez y Beatriz Santaella.

\footnotetext{
${ }^{12}$ Es necesario aclarar que tanto en este trabajo como en los otros que hicieran alusión a Abdulio Giudici o Abdulio Giudice, se trata de la misma persona.

${ }^{13}$ En la actualidad Facultad de Artes y Diseño de la Universidad Nacional de Cuyo.
} 
Lo Novedoso en las artes visuales argentinas de los años 70. El caso de Mendoza | 39

En su abordaje sobre los distintos usos de la categoría de vanguardia en el arte argentino de los años 60 y 70, Ana Longoni (2014) recupera la distinción que realiza Umberto Eco entre experimentalismo y vanguardia, donde entiende al experimentalismo como acción innovadora dentro de los límites del arte, mientras que, la vanguardia, se caracteriza por su decisión de ofender radicalmente las instituciones y convenciones. Siguiendo el desarrollo de Longoni, el Panorama de la Plástica mendocina que realiza Juárez, no solo reniega del excesivo convencionalismo de las instituciones de arte mendocinas, como jurados de premios y concursos, sino que explicita cuáles son los referentes del nuevo lenguaje visual: el cinetismo, el op y el Pop art.

Asimismo, Longoni (2014) también describe el conjunto de perspectivas acerca de la vanguardia artística en publicaciones ligadas a los sectores de la izquierda, dentro de las que reconoce como predominante la postura de impugnación hacia la vanguardia, por entendérsela como "moda extranjerizante o ejercicio meramente lúdico y superficial" (LONGONI, 2014:25). En el seguimiento de los derroteros que adquiere la idea de vanguardia en la revista del Partido Comunista Argentino Cuadernos de Cultura, la autora advierte diferentes sentidos, desde una postura enfáticamente en contra de la vanguardia y en defensa del realismo, que irá mutando hacia fines de los 60 hasta transformarse en pugna por definir cuál es la verdadera vanguardia. Es en el contexto enunciado por Longoni que podemos enmarcar las declaraciones de Raúl Capitani, como alguien que adhiere a las posturas de impugnación de la vanguardia.

\section{Los referentes del nuevo lenguaje visual: cinetismo, op y pop art}

Como ya se adelantó, las expresiones plásticas concebidas como progresistas por la vanguardia modernista mendocina, fueron el cinetismo, el Op y el Pop art. En este punto el medio mendocino coincidía con otras escenas de la región, como la de Buenos Aires con el Di Tella como foco de irradiación del Pop argentino, y las Bienales Kaiser en Córdoba, que impulsaron el Op y el cinetismo.

Un hecho paradigmático que consagra al cinetismo internacionalmente y signa la historia de su recepción en el arte argentino, es el premio otorgado a Julio Le Parc en la Bienal de Venecia de 1966. Asimismo, Cristina Rocca (2009) considera que este hecho condicionó el criterio de los jurados que premiaron la obra cinética de 
Carlos Cruz Diez en la III Bienal Americana de Arte, realizada en la ciudad de Córdoba el mismo año. A poco de recibir el Gran Premio de la Bienal de Venecia, Le Parc tuvo su primera exposición retrospectiva en el Instituto Di Tella, organizada por Ver y Estimar, en agosto de 1967.

El Op y el Pop art competían entre sí por el podio de la verdadera novedad. Cada premio que se otorgó a alguno de éstos despertó críticas entre los partidarios de la tendencia desplazada. Así, Romero Brest calificó de académica a la III Bienal Americana de Arte que premió a Carlos Cruz Diez (ROCCA, 2009), mientras que Córdova Iturburu renegaba del criterio que premió al Pop con las obras de Susana Salgado y Dalila Puzzovio, en el Premio Nacional Di Tella (1965) refiriéndose del siguiente modo:

Se mantienen firmes dentro del criterio de recompensar, sin mayores discriminaciones, lo que suponen nuevo; con frecuente despreocupación de que esas supuestas novedades cuentan con muchas decenas de años de existencia (CÓRDOVA ITURBURU, 9 de octubre de 1966).

Podemos reconocer en las palabras de Córdova Iturburu una valoración que lo emparenta con las de Capitani. Nos referimos a la distinción de Godgel (2013) entre dos actitudes hacia la emergencia de lo novedoso, planteándose estos con distancia escéptica sobre la supuesta novedad del Pop.

Por su parte, Iris Mabel Juárez, que se pronunciaba a favor de ambas expresiones, tuvo oportunidad de explayarse a propósito de la obra de Julio Le Parc, en una nota de página completa, publicada en el Diario Los Andes, en febrero de 1970. Allí la autora identifica la producción de Le Parc como referente del "arte de nuestro tiempo".

Por su parte, sin adherir expresamente al Pop ni al Op art, Marcelo Santángelo fue un artista que puede comprenderse como parte del vanguardismo modernista. En sus producciones pictóricas de principios de los 70, trabajó con módulos intercambiables y más tarde con proyecciones. Su obra Circulando (1971), configurada como un gran mural a partir de módulos intercambiables por el espectador, estaba en 
Lo Novedoso en las artes visuales argentinas de los años 70. El caso de Mendoza | 41 diálogo directo con la función lúdica del arte contemporáneo ${ }^{14}$ elaborada por Pierre Restany ${ }^{15}$.

La apuesta de Santángelo por un arte lúdico, se reforzaría con su búsqueda de una pintura para mirar, tocar y jugar, materializada en la serie Multifocales en coautoría con María Filomena Moyano. Por una nota del mismo Santángelo en la Revista Claves sobre su diálogo con Julio Le Parc, sabemos que los multifocales captaron la atención de éste último, quien estaba igualmente interesado en entablar un diálogo más directo con el espectador, en niveles sensoriales más que racionales (CLAVES, 8 de marzo de 1974: 28). En la misma entrevista, Santángelo pregunta a Le Parc si conocía la obra de Abdulio Giudici, puesto que él consideraba muy cercanas las búsquedas plásticas de ambos. Le Parc respondió negando conocerla.

\section{Nuevas concepciones del espectador. Marcelo Santángelo y la búsqueda de un arte "para mirar, tocar y jugar"}

Dentro de los fenómenos que podemos reconocer como novedosos en el campo de las artes visuales, a partir de la segunda mitad de los años 60 encontramos la transformación del tradicional rol del espectador. Éste es considerado ahora un actor participante y activo en la construcción del significado de la obra de arte. Enunciado de distintas maneras, textos diversos elaborados por autores diferentes convergen en este sentido.

En esta línea, podemos recoger las intenciones de Julio Le Parc de activación del espectador, la búsqueda de un "arte para mirar, tocar y jugar" de Marcelo Santángelo, y las ideas de Pierre Restany en torno de la función lúdica del arte contemporáneo.

Las indagaciones sobre el rol del espectador comenzaron a abrirse lugar en los años 60 y desde mediados de la década, experiencias como la Menesunda (1965) de Marta Minujín y Rubén Santantonín materializaron estas búsquedas. Esta obra particularmente y otras producciones de Minujín realizadas en el período han sido asociadas al Pop art, esto se

\footnotetext{
${ }^{14}$ Para un panorama sobre la discusión de este concepto de Restany a propósito del arte latinoamericano, puede consultarse Traba, M. (1973) "La resistencia" en M. Traba Dos décadas vulnerables en las artes plásticas latinoamericanas 1950-1970. México: Siglo XXI. 24-86

${ }^{15}$ El crítico y teórico del Noveau Réalisme francés, había participado como jurado del Premio Internacional Di Tella de 1964, convocado por Jorge Romero Brest.
} 
debe a que poseen una sensibilidad promotora del desparpajo y la diversión, que las emparenta con esta tendencia (LONGONI, 2004)

La función lúdica del arte contemporáneo cuya defensa es adjudicada a Pierre Restany por Marta Traba (TRABA; PIZARRO, 2005:94:), se refiere a una noción del arte-juego. De este concepto pueden extraerse dos cuestiones definitorias y distintivas del arte contemporáneo respecto del arte moderno. En primer lugar, la indiferenciación de lenguajes disciplinares, y en segundo lugar: la participación activa del espectador. La primera de estas, hace referencia a la fusión de lenguajes en la construcción de un objeto, por lo cual no es posible discernir si se trata de una pintura, escultura, danza, etc. La segunda, definitoria por excelencia del arte-juego, implica por parte del artista una acción programada, que requiere necesariamente de la comunicación activa del espectador. Según Marta Traba, Restany sostiene que "El arte-juego recurre al fetichismo puro del objeto, a los ritos múltiples que son susceptibles de engendrar la comunicación activa del espectador, a las nociones de control y relevo de la voluntad en el seno de una actividad programada" (TRABA; PIZARRO, 2005:94).

El interés por promover la interacción lúdica del espectador con la obra, también puede reconocerse en las obras de Marcelo Santángelo y la búsqueda de un arte "para mirar, tocar y jugar". Éste fue un actor clave en el campo cultural de Mendoza, su variada actividad como artista, docente, gestor y crítico le permitió entrar en contacto con distintos ámbitos de la cultura y la vida pública, como de experimentar en las artes sin reparos disciplinares. Un breve recorrido de la actividad de Santángelo es necesaria para dar cuenta de sus ideas.

Previo a los años 60, el autor ya demostraba interés en los cruces disciplinares. Había tenido un primer acercamiento a las artes escénicas, fue en los 50 la realización de su Cena surrealista (1953) un happening en que Santángelo convocó a artistas provenientes de la música, la danza, la plástica y la banda de la IV Brigada Aérea. Este happening resulta paradigmático por cuanto es una crítica a la división en géneros de las diferentes expresiones artísticas, que será retomada en sus textos críticos posteriores.

Tuvo un período de residencia en Buenos Aires, entre 1958 y 1964, donde fue supervisor e investigador de cinematografía en el Departamento de Radio Enseñanza y Cinematografía escolar que dependía del Ministerio de Educación de la Nación (COLLADO, agosto 2013). En aquellos años, Santángelo frecuentó el Instituto Di Tella y llegó a tener contacto con artistas como Marta Minujín y Alberto Greco. Ya en 
Lo Novedoso en las artes visuales argentinas de los años 70. El caso de Mendoza | 43

estos años empieza a trabajar en sus Multifocales, que consistieron en intervenir diapositivas que se proyectaban sobre músicos, recitadores y ya en los años 80 sobre bailarinas. Si bien sus multifocales van adquiriendo complejidad e incluyendo distintas variables sobre las superficies en que se proyectan, las inquietudes que inician estas experiencias visuales, pueden situarse en su período porteño. Es en Buenos Aires donde expuso por primera vez sus Multifocales, en la Galería Forum en septiembre de 1961

Durante los años 60 su producción encontró algunas reticencias en las instituciones del arte mendocino, pese a que había circulado con muy buenas críticas en España y Estados Unidos. A propósito de ello, la Revista Claves publica en setiembre de 1971 una nota que reúne las mejores críticas sobre sus exposiciones en España. Allí su producción es posicionada como referente del arte argentino y versan sobre su obra Circulando, una serie de composiciones multimodulares, realizadas a partir de piezas cuadradas de madera muy delgada, de $40 \mathrm{~cm}$ de lado, pintadas en superficie con una mezcla de cola de carpintero y acrílico, que aporta color y relieve a cada módulo. Las piezas tenían ganchos por detrás que permitían al espectador colgarla de cualquiera de sus cuatro lados y ubicarla en la composición general donde considere apropiado. Es decir que estaba planteada como una serie de composiciones posibles a partir de la participación del espectador, quien ubicaba los módulos según su preferencia, dado que el orden de los mismos no estaba prestablecido. En esto radica el espíritu de la "pintura para mirar, jugar y tocar" como el propio artista las definió en 1971, evidenciando el carácter interactivo.

Dentro de las reseñas españolas que recoge la Revista Claves, el Diario Ya de Madrid se refiere a Circulando como una experiencia, y entiende que "plantea relaciones con el espectador en planos todavía inéditos, convirtiéndose en una realidad más próxima y tangible, a tenor de las características de nuestro tiempo" (CLAVES, 10 de setiembre de 1971: 29) La interacción con el espectador a propósito de la que se aventura la reseña de Madrid, es uno de los grandes aportes de la obra de Santángelo a la narrativa contemporánea del arte mendocino.

Posterior a las reseñas de su obra, en marzo de 1974 se publica el primero de los artículos que el propio Santángelo escribe para la Revista Claves. Allí hace referencia a un encuentro con Julio Le Parc con quien tuvo oportunidad de intercambiar algunas ideas sobre el arte. En el artículo, Santángelo comenta "Le Parc también estaba trabajando sobre modulares y le interesó de sobremanera la inclusión del tacto en la 
percepción de nuestra pintura para mirar, tocar y jugar." (CLAVES, 8 de marzo de 1974: 28) Más adelante, hablando del interés que sus transparencias despertaron en Le Parc se refiere que éste le peguntó "sobre formas, filtros, proyectores, relaciones con el público, lugares donde las experimentamos, etc." (CLAVES, 8 de marzo de 1974: 28). Prosigue en su desarrollo diciendo que tuvieron oportunidad de intercambiar "algunas ideas sobre el hombre actual y la comunicación pictórica y necesidad de contribuir en niveles no discursivos" (CLAVES, 8 de marzo de 1974: 28).

Si bien su producción escrita ${ }^{16}$ posee un estilo muy particular, es posible enumerar algunas preocupaciones que encontramos reiteradas en sus textos. Al hablar del arte a menudo se refiere a éste como "un modo de conocimiento intuitivo" (SANTÁNGELO, 1983: 39 ${ }^{17}$ ). En esta dirección se puede comprender la incorporación del tacto como alternativa para generar otro tipo de acercamiento a la obra y profundizar la experiencia que ésta propicia. Es decir: como una inquietud asociada a la manera de entender el arte y de plantear sus producciones, directamente asociada a la función comunicativa del arte. En cuanto a esta función comunicativa del arte, surgen una serie de indagaciones, puesto que Santángelo percibe que la sociedad se ha transformado y, por tanto, el arte debe incorporar nuevos medios y lenguajes para comunicar sobre/en esta "nueva realidad" (SANTÁNGELO, 13 de noviembre de $\left.1978^{18}\right)$

Se hace evidente su interés en la incorporación de las tecnologías de la comunicación, a partir de las experiencias como supervisor e investigador de cinematografía en el Departamento de Radio Enseñanza y Cinematografía escolar, durante su residencia en Buenos Aires, entre 1958 y 1964. La experimentación con las nuevas tecnologías de comunicación de masas movilizó a Santángelo a realizar cortometrajes y

\footnotetext{
${ }^{16}$ El propio Santángelo publicó en 1983 un compendio de artículos publicados en la prensa en Santángelo. Santángelo. Diez años de papelones. 1974-1983. Mendoza: Edición del autor. En nuestro análisis sólo hemos considerado los que fueron publicados en la Revista Claves en diálogo con otros textos del artista escritos de manera contemporánea, o apenas transcurridos unos años, siempre dentro del período pautado en esta tesis, es decir hasta 1979.

${ }^{17}$ M. Santángelo (diciembre de 1978) "Invertir en obras de arte". Publicado en la revista El Espectáculo, Nro. 4, Mendoza, 1981.

${ }^{18}$ Ver: "¿Es posible una nueva realidad?" 13 de noviembre de 1978, fue publicado en la revista El Espectáculo, Nro.3, 1981. En Santángelo, 1983:42.
} 
Lo Novedoso en las artes visuales argentinas de los años 70. El caso de Mendoza | 45

experimentar las posibilidades del celuloide como soporte en la pintura, y de los proyectores como medio pictórico, lo que le permitió generar imágenes abstractas de gran atractivo visual, que a partir del estímulo retiniano generaban en los espectadores sensaciones hápticas. Pero también se interesó Santángelo en los medios masivos de comunicación y sus posibilidades de transmitir en tiempo real imágenes que llegaran a un sinnúmero de espectadores. Prueba de esto resulta la performance realizada en 1966 a propósito de la muerte de André Breton, que inspiró la realización de un funeral surrealista televisado, que fue transmitido por Canal 7 de Mendoza.

Las búsquedas e indagaciones de Marcelo Santángelo, estuvieron en sincronía no sólo con las de Julio Le Parc, sino también con el Happening para un jabali difunto ${ }^{19}$ que planteaban Eduardo Costa Roberto Jacoby y Raúl Escari, y la propuesta también televisada de Marta Minujín Simultaneidad en simultaneidad/Three Countries Happening, realización colectiva entre Minujin, Allan Kaprow (en Nueva York) y Wolf Vostell (en Berlín). Es decir, las tres propuestas: la de Minujín, la del Grupo de Arte en los Medios y la de Marcelo Santángelo fueron producidas en el mismo año: 1966, lo cual permite dar cuenta de por qué la figura de Santángelo estaba a la vanguardia, y es importante detenerse en sus desarrollos de forma individualizada.

19 "Entre los vanguardistas argentinos que experimentaron con medios de comunicación masiva, se destaca la iniciativa de un núcleo de artistas y teóricos. El manifiesto fundacional de ese grupo -integrado por Eduardo Costa (1940-), Roberto Jacoby (1944-) y Raúl Escari- es hoy reconocido como un documento crucial de los inicios del arte conceptual, no sólo en la Argentina sino también en el mundo. En 1966, se proponen la creación de un "nuevo género" que denominan "Arte de los medios de comunicación de masas". Su primera obra, conocida como El antihappening, consistió en la invención de un acontecimiento a ser transmitido por los medios masivos. A partir de la idea (bastante avanzada para la época) de que los medios construyen acontecimientos, quien(es) suscribe(n) deciden informar -mediante gacetillas, fotos trucadas y testimonios apócrifosacerca de un happening que nunca tuvo lugar. Distintos medios de comunicación reproducen la noticia, la cual es desmentida finalmente por el grupo. La primera nota aparecida fue la extensa crónica de Edmundo Eichelbaum en diario El Mundo". Longoni, Ana. Happening para un jabali difunto / Eduardo E. Eichelbaum Disponible

en: http://icaadocs.mfah.org/icaadocs/ELARCHIVO/RegistroCompleto/tabid/99/ doc/750866/language/es-MX/Default.aspx 
Nuevas relaciones obra-espectador. Julio le Parc y el espectadoractivado

En cuanto a Julio Le Parc, en los manifiestos que produjo en el marco del Groupe de Recherche d' Art Visuel, principalmente en "A propósito de arte-espectáculo, espectador-activo, inestabilidad y programación en el arte visual" (1962) el artista explicita su concepción sobre este nuevo rol del espectador, principalmente en el arte cinético, aunque se refiere al "arte visual actual" en términos generales. En el manifiesto de 1962, Le Parc comienza diciendo que

Es inútil ahora volver atrás y explicar por qué están superadas las clasificaciones tradicionales del arte visual (pintura, escultura, etc.) Limitando cada campo de realización, colocaban de un lado el objeto a contemplar y del otro situaban al espectador. Realizaciones actuales que superan estas limitaciones tratan de modificar la relación obra-espectador, requiriendo del espectador una participación de otro tipo (LE PARC, 2011 [1962]:312).

Más adelante enumera los distintos tipos de nuevas relaciones obra-espectador. El tipo espectador-estimulado, sería la relación que promueven las "obras cinéticas de superficie (cuadro)", que por medio de la estricta solicitación visual comprometen al espectador en el tiempo que concierne a la fisiología de la visión. Otro tipo de relación es enunciada como espectador-desplazamiento, esta sería la que propician las "obras cinéticas en volumen", en ellas el valor de la percepción reside en la estrecha relación entre el desplazamiento del espectador y las múltiples situaciones visuales que produce. Finalmente, describe otros dos tipos de obra que serían características del tipo de relación espectador-activado, que es por la cual suponemos aboga Le Parc.

Para comprender la noción de espectador-activado que propone el autor, es necesario volver sobre otras ideas que desarrolla en el mismo texto. Como vimos, al comienzo plantea como imperioso trascender las limitaciones que colocaban a la obra por un lado y al espectador por el otro, entendiendo ambos como parte de un binomio constitutivo del arte actual, que se presenta de distinta manera en cada tipo de las relaciones 
Lo Novedoso en las artes visuales argentinas de los años 70. El caso de Mendoza | 47

mencionadas. Seguido de esto, existen dos aspectos importantes para la comprensión de la relación espectador-activado. Uno de ellos es la descripción del fenómeno estético como un circuito: concepciónrealización-visualización-percepción. A este circuito Le Parc agrega el estado de modificación. El estado de modificación será el que posibilite la relación espectador-activado, ésta se realiza en las obras de "participación real (manipulación de elementos)" donde el espectador recrea las obras transformables. Aquí se evidencia la necesidad de trascender los límites que fijaban roles a la obra y al espectador, puesto que este tipo de realizaciones, se basan en la doble participación real del realizador y del espectador, sobre la concepción de base que el primero presenta de la obra. Esto quiere decir que el realizador debía

...prever de antemano todas las condiciones de desarrollo de la obra, determinar con claridad sus modalidades para poder dejarla realizarse en el espacio y en el tiempo, sometida a contingencias previstas de carácter determinado o indeterminado, que provienen del medio en que se desenvuelve y de la participación activada o activa del espectador (LE PARC, 2011 [1962]:315).

Hemos hallado además que, ya en julio de 1968, Iris Mabel Juárez estaba disertando sobre la obra de Julio Le Parc en el Museo de Arte Moderno de Mendoza, como parte de un ciclo de conferencias organizado por la Escuela Superior de Artes. (LOS ANDES, 20 de julio de 1968) Por ello, sabemos que en Mendoza circulaban las ideas de Julio Le Parc sobre el espectador activado, desde los 60. En el artículo escrito por Iris Mabel Juárez sobre Le Parc y el arte de nuestro tiempo, la autora recupera algunas de las ideas expuestas por el artista en el manifiesto de 1962. Asimismo, recuperando en cierto modo la recepción de sus ideas en el medio mendocino, describe algunos reproches que se le hacen a Le Parc y sus obras cinéticas. Juárez se refiere a dos cuestiones: el uso de motores para generar el movimiento de sus piezas, y a la "arbitrariedad y la participación del azar en sus obras" (JUÁREZ, 22 de febrero de 1970) La autora se alza en defensa de la producción de Le Parc y, comparándolo con las obras informalistas, se refiere a que "son el resultado de la casualidad y nadie puede negar su valor a este movimiento". Más adelante les compara también con la música aleatoria: 
Depende en buena medida del azar, en la cual el compositor construye cierto tipo de estructuras y deja otras libradas a la improvisación de los ejecutantes o construye todas las estructuras pero permite o exige que los intérpretes las ordenen a su gusto. De ese modo se obtiene una música que nunca se repite, como las imágenes irrepetibles de Le Parc, y esa música es creada definitivamente en el momento de su ejecución (JUÁREZ, 22 de febrero de 1970).

Juárez se refiere a la participación de los ejecutantes como parte de la construcción final de una pieza, y busca distinguir esta modalidad de lo que implicaría dejar una obra librada al azar. Si bien Le Parc no hace uso del concepto de azar o aleatoriedad, sí reconoce que en la idea de modificación que introdujo al tradicional circuito de concepciónrealización-percepción, hay un nexo con la noción de inestabilidad. La posibilidad de que el espectador modifique la concepción original del artista, en los 70 fue malinterpretada como un ceder a la aleatoriedad el compromiso de la ejecución final. Por lo que leemos en Juárez, Le Parc, e incluso Santángelo, se trata de sumar al espectador en el proceso de ejecución, no de desaparecer al artista, sino de erradicar la jerarquía propia del arte tradicional, y comenzar el camino hacia un proceso -si se quiere- más horizontalista.

Esa distancia entre la concepción que los artistas tenían del espectador activo y la comprensión del medio artístico sobre esta idea, es propia de las innovaciones. Se comprende que esta lectura es muy lejana al sentido en que lo planteaban los productores, la participación del espectador está contemplada desde el momento de concepción de la obra, como lo demuestra el concepto de programación enunciado por Le Parc:

La noción de programación (a menudo utilizada por la Nueva Tendencia) engloba la manera de concebir, realizar y presentar obras inestables. Se trata de prever de antemano todas las condiciones de desarrollo de la obra, determinar con claridad sus modalidades para poder dejarla 
Lo Novedoso en las artes visuales argentinas de los años 70. El caso de Mendoza | 49 realizarse en el tiempo y el espacio, sometida a contingencias previstas de carácter determinado o indeterminado, que provienen el medio en que se desenvuelve la participación activada o activa del espectador (LE PARC, 2011 [1962]:316).

En la afirmación de Le Parc se evidencia cómo la intervención del espectador estaba programada como parte de las condiciones de desarrollo de la obra.

\section{A modo de conclusión}

En un breve repaso por los objetivos planteados para el presente artículo, se propuso conocer cuáles fueron las distintas posiciones que emergen de los debates sobre las nuevas formas de expresión en las artes visuales, y cómo podemos entender la recepción de éstas en tanto alternativas innovadoras dentro del campo artístico visual de Mendoza.

Después de repasar las distintas posiciones que sostienen Iris Mabel Juárez y Raúl Capitani sobre el estado actual de la plástica mendocina a fines de los 60, estamos en condiciones de afirmar que la irrupción del Pop art puede ser concebida como una innovación, y como tal, no tuvo una recepción unánime en el medio plástico local. Por el contrario, despertó aversiones y cuestionamientos, propios del arte de vanguardia.

Los agentes vinculados a la vanguardia modernista, sostuvieron expectativas de "modernizar" el arte. Entre las instituciones que promovieron este espíritu de actualización vanguardista encontramos al Museo de Arte Moderno de Mendoza y el Departamento de Extensión Universitaria de la Universidad Nacional de Cuyo. Ambos promovieron entre sus actividades los cursillos que pretendían "facilitar la comprensión de las situaciones culturales y humanas que crea el arte moderno", dirigidos por Abdulio Giudici entre 1966 y 1969. Allí se plantea la premura y la urgencia de conocer el arte contemporáneo, como también la necesidad de modernización cultural, que agitó a la vanguardia modernista. Participó de ellos en varias ocasiones Iris Mabel Juárez, como por ejemplo en julio de 1968, año en que disertó sobre la obra de Julio Le Parc como parte de un ciclo de conferencias organizado por la Escuela Superior de Artes en el Museo de Arte Moderno. 
Los medios por los que circularon las ideas sobre lo novedoso en las artes visuales fueron variados. Entre las revistas culturales, se mencionó el diagnóstico de la plástica que Iris Mabel Juárez presentó en la Revista Enfoques. Allí, Juárez propone una visión del campo en conflicto, entre expresiones progresistas como el Pop, el Op art y el cinetismo, y el apático convencionalismo. Asimismo, hubo otros artistas mendocinos que como Raúl Capitani vieron con desconfianza las manifestaciones vinculadas al Op y el Pop art, por cuanto las consideraron modas extranjerizantes. Esto se evidencia en las palabras de Capitani en Diario Mendoza al referirse a estas tendencias en términos de "teatro y aparatosidad", llegando a compararlas con las modas femeninas o los cantantes de moda, por cuanto "hay que cambiarlos de cartelera semanalmente". Como si la novedad y la experimentación fueran algo malo en sí mismos, se refiere a al artista-bufón que es incitado a la "peligrosa tendencia, de querer ser diferente".

Esta impugnación hacia la vanguardia que los sectores de la izquierda impusieron como "moda extranjerizante o ejercicio meramente lúdico y superficial", se dio a conocer en el caso mendocino por artículos en la prensa periódica. También desde las páginas de la Revista Claves, las críticas de Fernando Lorenzo reseñaron la actividad plástica de Mendoza en varias ocasiones, y desde 1971 empezó a escribir allí el artista Marcelo Santángelo, quien también propulsó la participación activa del espectador en sus obras.

Pero, además de las publicaciones impresas, sea en formato de revista cultural o de periódico masivo, las nuevas formas de expresión circularon con el apoyo institucional del Museo de Arte Moderno y la Universidad Nacional de Cuyo, en forma de cursillos, conferencias y exposiciones de obras de arte, pero también se materializaron en producciones artísticas. Estas nuevas expresiones artísticas no sólo fueron novedosas por el uso de materiales industriales y modos sintéticos, sino que promovieron nuevos modos de producción/interacción con el espectador. Probablemente esta sea la mayor innovación que se produjo en las artes visuales a partir de la segunda mitad de los sesenta, nos referimos a la incorporación del espectador en la realización final de la obra.

La comunicación pictórica y la necesidad de contribuir en niveles no discursivos, fueron los móviles que agitaron a los artistas como Santángelo y Julio Le Parc a promover la interacción con el espectador como fundamento primero de sus obras. Así como las piezas cinéticas de Le Parc incorporan la posibilidad de modificar lo pautado por el artista 
Lo Novedoso en las artes visuales argentinas de los años 70. El caso de Mendoza | 51 tras la "participación real" del espectador en obras que implicaban manipular elementos; la pintura para mirar, tocar y jugar de Santángelo incluyó este mismo principio en su serie Circulando (1971). Ambos artistas fueron conscientes de la necesidad de trascender las limitaciones que colocaban a la obra por un lado y al espectador por el otro para poder pensar y percibir estos nuevos modos de relacionar a la obra y al espectador, que se constituyen mutuamente. 
52 | María Paula Pino Villar

Apéndice imágenes

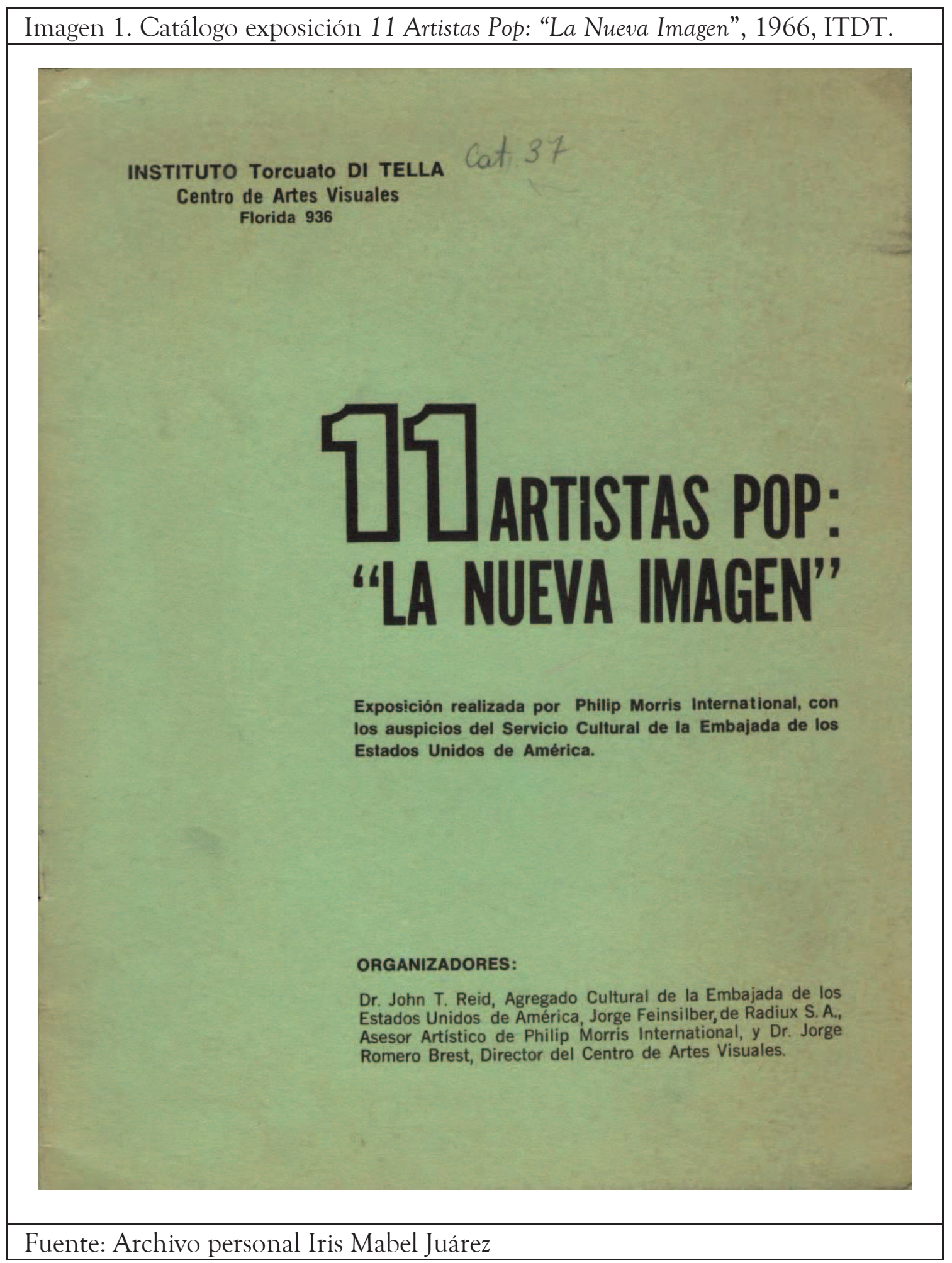

Caderno de Letras, no 31, Mai-Ago - 2018 - ISSN 0102-9576 
Lo Novedoso en las artes visuales argentinas de los años 70. El caso de Mendoza | 53

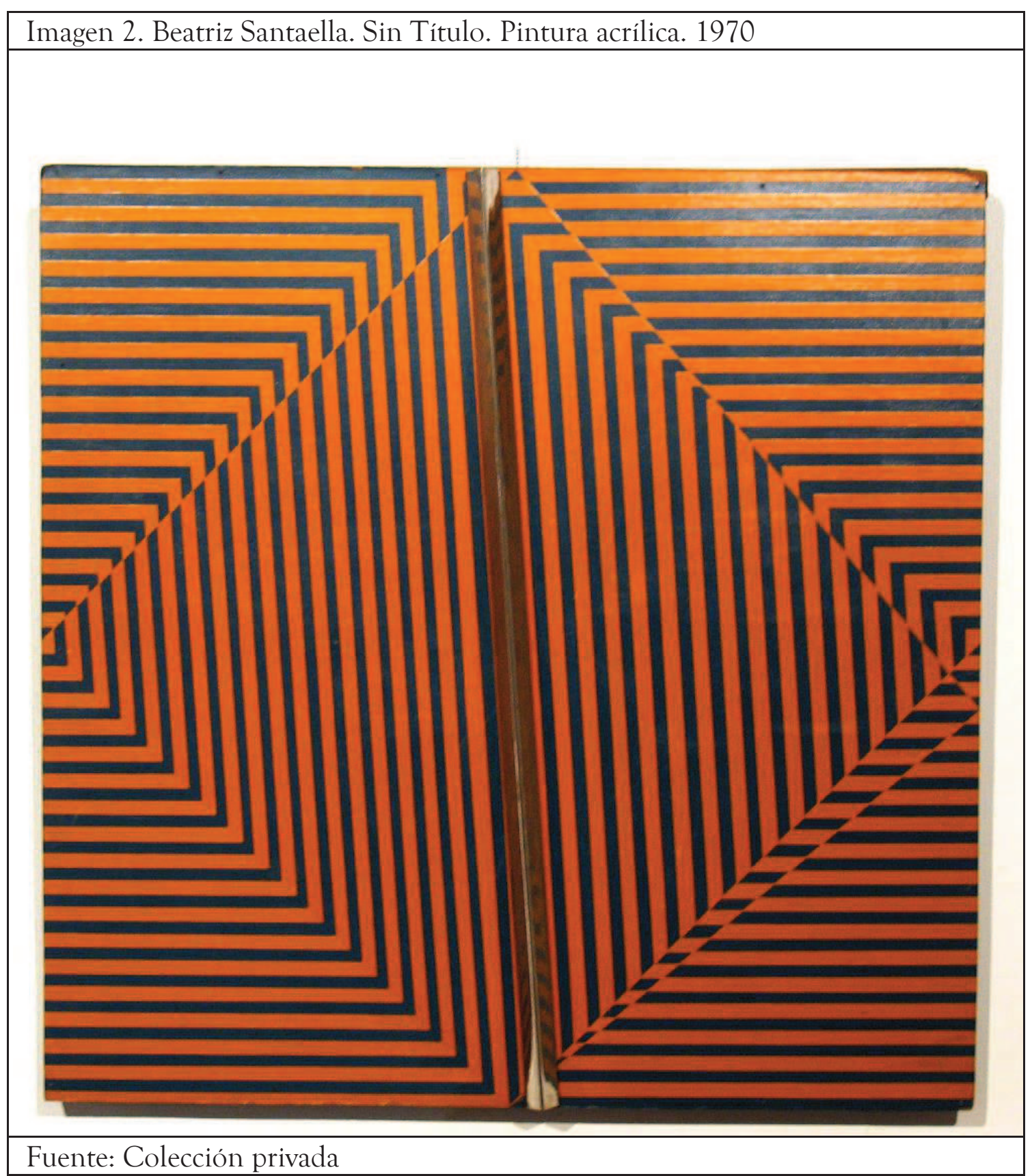


54 | María Paula Pino Villar

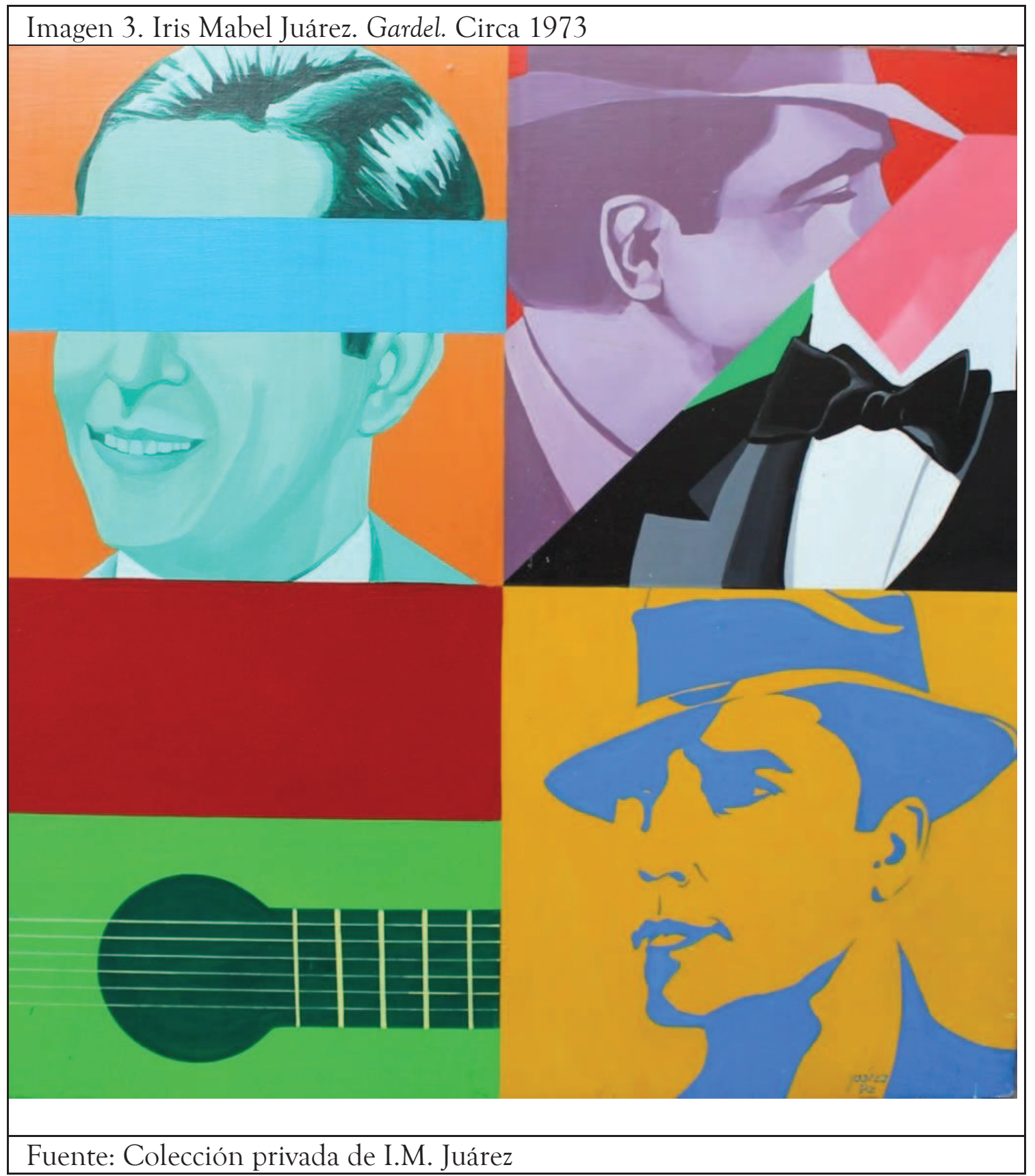

Caderno de Letras, no 31, Mai-Ago - 2018 - ISSN 0102-9576 
Lo Novedoso en las artes visuales argentinas de los años 70. El caso de Mendoza | 55

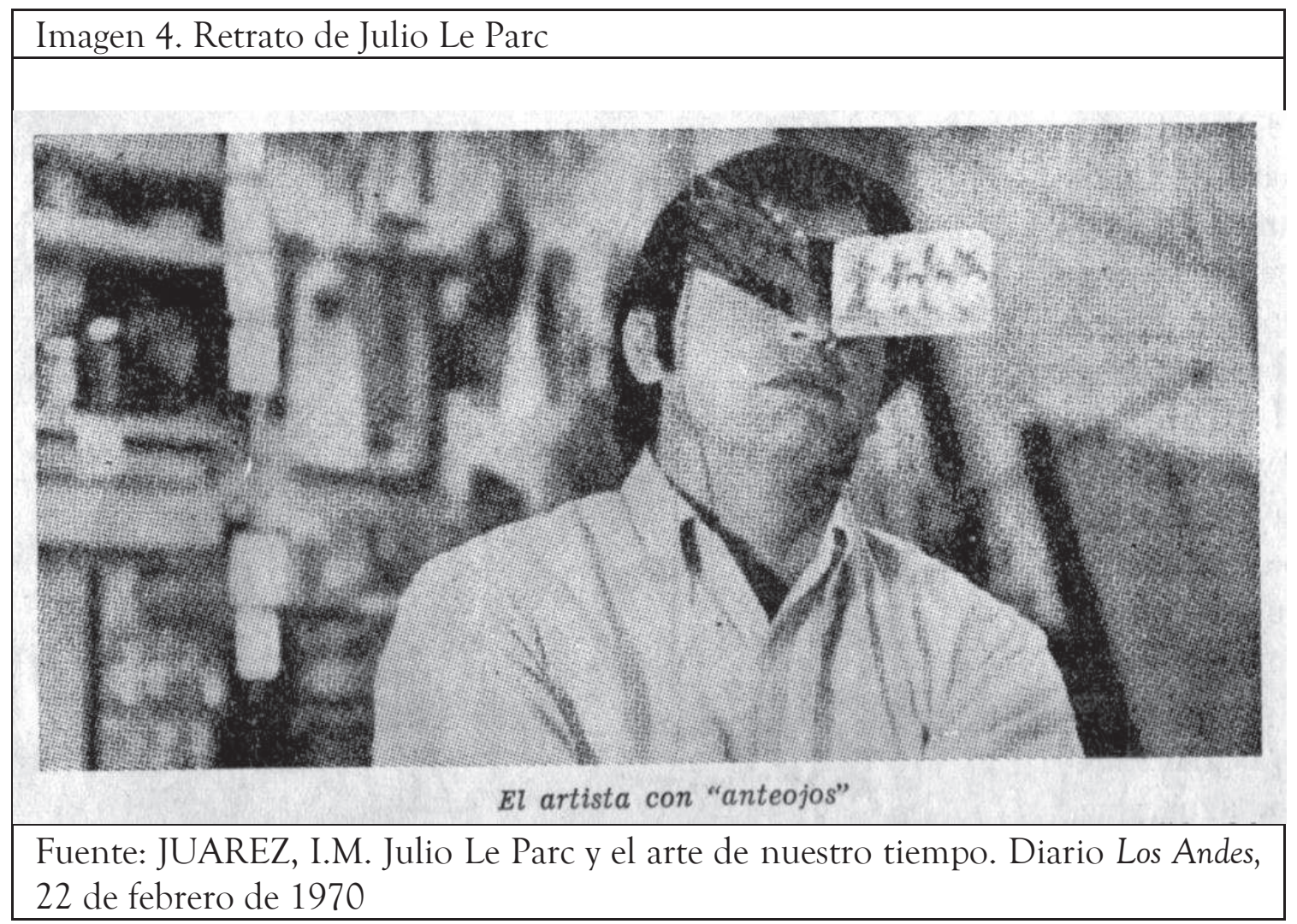

\section{BIBLIOGRAFÍA}

ALONSO, Rodrigo. Imán: Nueva York. Arte argentino de los años 60. Buenos Aires: Fundación PROA, Julio-Octubre 2010

BOURDIEU, Pierre. Razones prácticas. Sobre la teoría de la acción. Barcelona: Anagrama, 1997

CHIAVAZZA, Pablo, Lo político de la poética. Arte mendocino de los años '70. Museo del Área Fundacional, Mendoza, abril 2016

CLAVES. ¡Circulen, Circulen!, Mendoza, 10 de setiembre de 1971

COLLADO, Andrés. "Modernización y renovación en el arte en Mendoza. Santángelo en la encrucijada desarrollista”. Segunda parte. Revista Estampa 11. Núm. 3 y 4. Mendoza: SeCTyPUNCuyo. Agosto 2013: 84-95. Disponible: https://issuu.com/estampa11/docs/revista 3 y

CÓRDOVA ITURBURU, Cayetano. Op art y pop art en el Di Tella. El Mundo (Buenos Aires), 9 de octubre de 1966

GILMAN, Claudia. Entre la pluma y el fusil: debates y dilemas del escritor revolucionario en América Latina. 2da edición. Buenos Aires: Siglo Veintiuno, 2012 
GIUDICI, Abdulio. Cursillo acerca de arte moderno. Mendoza: Departamento de Extensión Universitaria, Universidad Nacional de Cuyo, 1966

GIUNTA, Andrea. Vanguardia, internacionalismo y política. Arte argentino en los años sesenta. Buenos Aires: Paidós, 2001

GODGEL, Víctor. Cuando lo nuevo conquistó América. Prensa moda y literatura en el siglo XIX. Buenos Aires: Siglo XXI, 2013

JUÁREZ, Iris Mabel. Panorama de la Plástica mendocina, Revista Enfoques. (Mendoza) 13 de junio de 1970.

. Julio Le Parc y el arte de nuestro tiempo, Los Andes (Mendoza) 22 de febrero de 1970.

KING, John. El Di Tella y el desarrollo cultural argentino en la década del sesenta. Buenos Aires: Ediciones de Arte Gaglianone, 1985

LE PARC, Julio. GRAV. A propósito del arte-espectáculo, espectadoractivo, inestabilidad y programación en el arte visual. In: Manifiestos argentinos: políticas de los visual 1900-2000. Buenos Aires: Adriana Hidalgo, 2011 [1962]

LONGONI, Ana. Vanguardia y revolución. Arte e izquierdas en la Argentina de los sesenta-setenta. Buenos Aires: Ariel, 2014

LORENZO, Fernando. XXII Salón de Cuyo. Revista Claves (Mendoza) 6 de octubre de 1973

LOS ANDES, Sobre Julio Le Parc habrá una Charla en el Museo Municipal, Los Andes (Mendoza) 20 de julio de 1968

MASOTTA, Oscar. Revolución en el arte. Pop-art, happening y arte de los medios en la década del sesenta. Buenos Aires: Edhasa, 2004

MENDOZA, La plástica en San Rafael, Mendoza (Mendoza) 19 de octubre de 1969

QUIROGA, Wustavo, ed. Feria de América: Vanguardia invisible. Mendoza: Fundación del Interior, 2012

ROCCA, María Cristina. Arte, modernización y guerra fría. Las bienales de Córdoba en los sesenta. Córdoba: UNC, 2009

SANTÁNGELO, Marcelo, Cultura de la patria chica y de la patria grande, Revista Claves, Año IV N 90, Mendoza, 8 de marzo de 1974

. Diez años de papelones. 1974-1983. Mendoza: Edición del autor, 1983

TERÁN, Oscar, Lección 10. Violencia política, terrorismo estatal y cultura (1970-1980) In: Historia de las ideas en la Argentina: diez lecciones iniciales, 1810-1980. Buenos Aires: Siglo XXI, 2008 
Lo Novedoso en las artes visuales argentinas de los años 70. El caso de Mendoza | 57

TRABA, Marta; PIZARRO, Ana. Mirar en América. Venezuela: Fundación Biblioteca Ayacucho, 2005.

TRABA, Marta. Dos décadas vulnerables en las Artes Plásticas Latinoamericanas 1950/1970. México: Siglo XXI, 1973.

ZALAZAR, Oscar. Raúl Capitani. Mendoza: Museo Municipal de Arte Moderno de Mendoza, 24 de abril - 26 de mayo de 2014

Recebido em: 07/07/2018

Aceito em: 23/07/2018 